EGU2020-2870

https://doi.org/10.5194/egusphere-egu2020-2870

EGU General Assembly 2020

(c) Author(s) 2020. This work is distributed under

the Creative Commons Attribution 4.0 License.

\title{
The first steps of iodine gas-to-particle conversion as seen in the lab: constraints on the role of iodine oxides and oxyacids
}

\author{
Juan Carlos Gomez Martin ${ }^{1}$, Tom Lewis², Manoj Kumar ${ }^{3}$, John Plane ${ }^{4}$, Joseph Francisco ${ }^{3}$, and \\ Alfonso Saiz-Lopez ${ }^{2}$ \\ ${ }^{1}$ Instituto de Astrofisica de Andalucia - CSIC, Solar System Department, Granada, Spain (jcgomez@iaa.es) \\ ${ }^{2}$ Department of Atmospheric Chemistry and Climate, Institute of Physical Chemistry Rocasolano, CSIC, Madrid, Spain \\ ${ }^{3}$ University of Pennsylvania, School of Arts and Sciences, Department of Chemistry, Philadelphia, PA 19104-6323, USA \\ ${ }^{4}$ School of Chemistry, University of Leeds, LS2 9JT Leeds, UK
}

The photooxidation of gas phase iodine-bearing molecules emitted by marine biota leads to intense particle nucleation events in the coastal and polar marine boundary layer ${ }^{1-3}$. The ubiquity of iodine in the marine atmospheric environment ${ }^{4-7}$ has suggested that this may be a previously unrecognized global source of new aerosol particles ${ }^{8}$. Atmospheric modeling is required in order to evaluate the importance of this process, but a substantial lack of understanding of the gas-toparticle conversion mechanism is hindering this effort, especially regarding the gas phase chemistry of the nucleating molecules (iodine oxides ${ }^{9,10}$ and/or oxyacids ${ }^{7}$ ) and the formation kinetics of molecular clusters. To address this problem, we have conducted new flow tube laboratory experiments where pulsed laser photolysis or continuous broad-band photolysis of $\mathrm{I}_{2} / \mathrm{O}_{3}$ mixtures in air are used to generate iodine radicals in the presence of atmospherically representative mixing ratios of water vapor. The molecular reactants and the resulting molecular products are detected by time-resolved VUV laser photo-ionization time-of-flight mass spectrometry. High-level quantum chemistry and master equation calculations and gas kinetics modelling are used to analyse the experimental data. In this presentation we discuss our results and their implications for the interpretation of field meassurements and for the implementatiion of an iodine oxide particle formation mechanism in atmospheric models.

References:

1. Hoffmann, T., O'Dowd, C. D. \& Seinfeld, J. H. lodine oxide homogeneous nucleation: An explanation for coastal new particle production. Geophys. Res. Lett. 28, 1949-1952 (2001).

2. McFiggans, G. et al. Direct evidence for coastal iodine particles from Laminaria macroalgae linkage to emissions of molecular iodine. Atmos. Chem. Phys. 4, 701-713 (2004).

3. O'Dowd, C. D. et al. Marine aerosol formation from biogenic iodine emissions. Nature 417, 632-636 (2002).

4. Prados-Roman, C. et al. lodine oxide in the global marine boundary layer. Atmos. Chem. Phys. 
15, 583-593, doi:10.5194/acp-15-583-2015 (2015).

5. Schönhardt, A. et al. Simultaneous satellite observations of $\mathrm{IO}$ and $\mathrm{BrO}$ over Antarctica. Atmos. Chem. Phys. 12, 6565-6580, doi:10.5194/acp-12-6565-2012 (2012).

6. Mahajan, A. S. et al. Concurrent observations of atomic iodine, molecular iodine and ultrafine particles in a coastal environment. Atmos. Chem. Phys. 10, 27227-27253 (2010).

7. Sipilä, M. et al. Molecular-scale evidence of aerosol particle formation via sequential addition of HIO3. Nature 537, 532-534, doi:10.1038/nature19314 (2016).

8. Saiz-Lopez, A. et al. Atmospheric Chemistry of Iodine. Chem. Rev. 112, 1773-1804, doi:DOI: $10.1021 /$ cr200029u (2012).

9. Gómez Martín, J. C. et al. On the mechanism of iodine oxide particle formation. Phys. Chem. Chem. Phys. 15, 15612-15622, doi:10.1039/c3cp51217g (2013).

10. Saunders, R. W., Mahajan, A. S., Gómez Martín, J. C., Kumar, R. \& Plane, J. M. C. Studies of the Formation and Growth of Aerosol from Molecular lodine Precursor. Z. Phys. Chem. 224, 1095-1117 (2010).

How to cite: Gomez Martin, J. C., Lewis, T., Kumar, M., Plane, J., Francisco, J., and Saiz-Lopez, A.: The first steps of iodine gas-to-particle conversion as seen in the lab: constraints on the role of iodine oxides and oxyacids, EGU General Assembly 2020, Online, 4-8 May 2020, EGU2020-2870, https://doi.org/10.5194/egusphere-egu2020-2870, 2020 